\title{
Amyotrophic lateral sclerosis: a double-blind crossover trial of thyrotropin-releasing hormone
}

\author{
KEIJI IMOTO, KYOKO SAIDA, KYOKO IWAMURA, TAKAHIKO SAIDA, \\ HIROSHI NISHITANI
} From the Department of Neurology and Clinical Research Centre, Utano National Hospital, Kyoto 616,
Japan

SUMMARY A double-blind crossover trial was conducted of thyrotropin releasing hormone treatment in six patients with amyotrophic lateral sclerosis. Patients received $4 \mathrm{mg}$ of thyrotropin releasing hormone intramuscularly daily during the two-week treatment period. Although three patients reported subjective improvement, objective evaluation failed to demonstrate therapeutic effectiveness of thyrotropin releasing hormone in this dosage.

Based on evidence that thyrotropin releasing hormone (TRH) may be a trophic factor or transmitter of motor neurons, ${ }^{1-4}$ Engel et al gave thyrotropin releasing hormone in a massive dose $(200 \mathrm{mg})$ to patients with amyotrophic lateral sclerosis and reported an increase in muscle strength. ${ }^{5}$ Yamane $e t$ $a l$ in an open trial also reported that $0.5-2 \mathrm{mg}$ of thyrotropin releasing hormone is effective in $56 \%$ of patients with amyotrophic lateral sclerosis. ${ }^{\circ}$ We evaluated the therapeutic effectiveness of TRH for amyotrophic lateral sclerosis in a double-blind crossover trial.

\section{Methods}

Diagnosis of amyotrophic lateral sclerosis in patients accepted for the trial was made by a neurologist after appropriate electrodiagnostic and radiological studies. Patients entering the trial (four women and three men, aged 37 to 69 years) gave informed consent. Their amyotrophic lateral sclerosis scores using the Norris scale? ${ }^{7}$ ranged from 57 to 79 (mean: 70-3) before the treatment. Five patients were ambulatory and two were confined to a wheelchair. Antispastic medications were withheld during the study period, and sedative drugs on the day before and on the morning of the evaluation.

After a two-week washout period, the study was carried

Address for reprint requests: Dr K Imoto, Department of Neurology, Utano National Hospital, Narutaki, Ikyo, Kyoto 616, Japan.

Received 24 April 1984 and in revised form 20 June 1984.

Accepted 25 June 1984

out in a double-blind crossover design with two treatment periods of two weeks each, during which $4 \mathrm{mg}$ of TRH (administered in the form of TRH tartrate) or placebo (5\% sorbitol solution) was injected intramuscularly daily. Each treatment period was followed by three-week observation period on no treatment. Treatment assignment was randomised; three patients began with TRH, and four patients with placebo. The patients were evaluated weekly throughout 12 weeks. The evaluation was performed in the morning, before the injection of TRH or placebo during the treatment periods.

The items of the objective evaluation included (a) bulbar functions: time for speaking name and address, clarity of speech, time for swallowing a cup of water, and ability to protruding the tongue, (b) function of upper extremities: active range of motion of the shoulder joints, grasping power, time for moving a row of six pegs, and time for writing name and address, (c) function of the lower extremities: time for walking up and down a flight of stairs, and time for walking 20 metres. When a patient could not perform a certain item of the evaluation because of the severe disability, the test of the item was omitted for that patient during the study period. Routine blood chemistry, urinalysis and thyroid function tests were conducted before and after each treatment period on each patient.

\section{Statistical analysis}

Since the symptoms were expected to progress even during the 12 week test period, it was inappropriate to simply compare the data of the TRH treatment period with that of the placebo period. Making assumption that TRH is not effective, a regression line was calculated with the minimal square method for each item of the evaluation for each patient. The deviation of the data from this regression line was calculated, and the deviation of the TRH treatment 


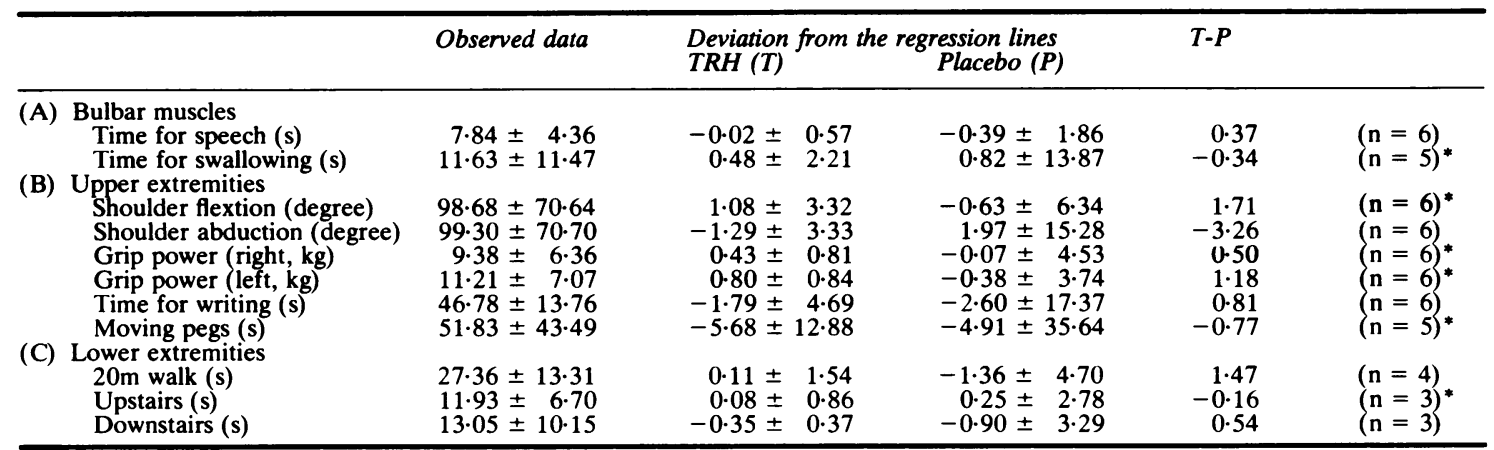

Results are mean $\pm \mathrm{SD}$.

$\mathrm{n}=$ number of patients.

In 11 subtests, TRH score was better than placebo in $6\left(^{*}\right)$, and placebo better than TRH in 5; none of these changes reached statistical significance.

period $(T)$ was compared with that of the placebo period (P). A $t$ test was done to determine the significance.

\section{Results}

Six out of seven patients completed the study. One patient developed pneumonia during the study and was withdrawn. There were no changes in the scores for tongue protrusion and speech clarity. TRH appeared effective in some items of the evaluation such as grip power and time for moving pegs, and ineffective in others such as time for $20 \mathrm{~m}$ walk. However, statistical analysis failed to demonstrate significant improvement in any item of the evaluation (table).

Three of the patients felt subjectively better while they were receiving TRH and none while receiving placebo. They reported increased power of the fingers, improved swallowing, or less spasticity of legs. However, objective evaluation failed to confirm these subjective changes.

Two patients reported nausea after injection of TRH. Routine blood chemistry, urinalysis, and thyroid function tests revealed no abnormalities after the trials.

\section{Discussion}

Daily administration of $2 \mathrm{mg}$ of TRH has been reported to improve symptoms of cerebellar ataxia. ${ }^{8}$ Yamane et al in an open trial in amyotrophic lateral sclerosis $^{6}$ reported the efficacy of this dosage. We therefore used $4 \mathrm{mg}$ of TRH daily in our patients, hoping TRH in this dosage could be effective for amyotrophic lateral sclerosis. However, in this double-blind crossover study, we unfortunately failed to demonstrate any therapeutic effectiveness.
The reason for the subjective efficacy of TRH in three patients in our study is not clear. It is possible that the methods of evaluation were not accurate enough to detect minor changes. But it is also conceivable that a possible psychologically exciting action of TRH was responsible. Similar psychological arousal effects in several of nine patients with amyotrophic lateral sclerosis were observed after intrathecal injection of 50-1000 $\mu \mathrm{g}$ of TRH despite its failure to increase muscle strength or to reduce spasticity. ${ }^{9}$ Despite these disappointing short-term results, however, and in absence of any satisfactory treatment for amyotrophic lateral sclerosis, clinical studies of long-term or higher dose administration of TRH may be justified.

We thank Drs SA Kuno, T Konishi, Y Goban, and T Kawanishi for referring their patients and Takeda Chemical Industries, Ltd, Osaka, Japan for providing TRH and placebo preparation.

\section{References}

' Hokfelt T, Fuxe K, Johansson O, Jeffcoate S, White N. Distribution of thyrotropin-releasing hormone (TRH) in the central nervous system as revealed with immunohistochemistry. Eur J Pharmacol 1975;34:389-92.

${ }^{2}$ Kardon FC, Winokur A, Utiger RD. Thyrotropinreleasing hormone in rat spinal cord. Brain Res 1977;122:578-81.

${ }^{3}$ Winokur A, Utiger RD. Thyrotropin-releasing hormone: regional distribution in rat brain. Science 1974; 185:265-7.

${ }^{4}$ Cooper BR, Boyer CE. Stimulant action of thyrotropin releasing hormone on cat spinal cords. Neuropharmacology 1978;17:153-6.

s Engel WK, Siddique T, Nicoloff JT. Effect on weakness 
and spasticity in amyotrophic lateral sclerosis of tyrotropin-releasing hormone. Lancet 1983;2:73-5.

- Yamane K, Osawa M, Kobayashi I, Maruyama S. Therapeutic trial of TRH (thyrotropin releasing hormone) in amyotrophic lateral sclerosis. Progress in Medicine (Japan) 1984;128:235-6.

${ }^{7}$ Norris FH Jr, Calanchini PR, Fallat RJ, Panchari S, Jewett $B$. The administration of guanidine in amyotrophic lateral sclerosis. Neurology (Minneap)
1974;24:721-8.

${ }^{8}$ Sobue I, Takayanagi T, Nakanishi T, et al. Controlled trial of thyrotropin releasing hormone tartrate in ataxia of spino-cerebellar degenerations. J Neurol Sci 1983;61:235-48.

${ }^{9}$ Saida T, Imoto K, Saida K, Iwamura K, Nishitani H. Trials of thyrotropin releasing hormone (TRH) treatment in patients with amyotrophic lateral sclerosis. (abstract) Ann Neurol 1984;16:109 